\title{
Liberalismo Perfeccionista y Liberalismo Político (Parte II)
}

\section{Perfectionist Liberalism and Political Liberalism (Part II)}

\author{
EL RESPETO EN EL LIBERALISMO POLÍTICO ES, ANTE TODO, RESPETO A LAS PERSONAS, NO \\ RESPETO POR LAS DOCTRINAS QUE SOSTIENEN, EL FUNDAMENTO DE ESAS DOCTRINAS O \\ CUALQUIER OTRA COSA SOBRE ELLAS.
}

\begin{abstract}
Resumen: En la primera parte del artículo la autora discute dos variantes de liberalismo a partir del pensamiento de destacados filósofos. Por un lado, analiza las ideas de Isaiah Berlin y Joseph Raz como ejemplos de liberalismo perfeccionista y, por el otro, las de John Rawls y Charles Larmore como
\end{abstract}

(*) Filósofa por la Universidad de Harvard. Bachelor of Arts en la Universidad de Nueva York. Master of Arts y Philosopae Doctor en la Universidad de Harvard. Ernst Freund Distinguished Service Professor de Derecho y Ética en la Facultad de Derecho de la Universidad de Chicago. Ha sido catedrática en las universidades de Harvard, Brown, Oxford. Premio Príncipe de Asturias de Ciencias Sociales del año 2012. Correo electrónico: martha_nussbaum@law.uchicago.edu

${ }^{(* *}$ Este artículo fue originalmente publicado por la Editorial Wiley como: Martha C. Nussbaum, "Perfectionist Liberalism and Political Liberalism," Philosophy \& Public Affairs 29 (2011): 3-45. @ 2011 Wiley Periodicals, Inc. Philosophy \& Public Affairs 29, No. 1.

Agradecemos gentilmente el permiso de la autora Martha C. Nussbaum para su traducción y publicación, en esta edición de la Revista IUS ET VERITAS corresponde la segunda parte. La traducción estuvo a cargo de José Enrique Sotomayor Trelles, abogado (summa cum laude) por la PUCP. Ex Becario del Máster en Democracia Constitucional e Imperio de la Ley por la Universidad de Génova (Italia). Candidato a magíster en Filosofía por la PUCP y Economía por la UNMSM. Se ha añadido algunas notas del traductor identificadas con la abreviatura (NT) para procurar esclarecer o enriquecer algunos pasajes de la obra traducida.

${ }^{* * *}$ Este artículo fue escrito inicialmente para una conferencia sobre Isaiah Berlin en la Universidad de Harvard, en setiembre de 2009. La autora agradece por los útiles comentarios de Erin Kelly y Thomas Scanlon en dicha ocasión. Las ideas principales se originaron en una discusión tras una presentación de Josehp Raz en el Law Philosophy Workshop de la Universidad de Chicago en noviembre de 2008, y fueron publicadas en el Blog de la Facultad de Derecho de la Universidad de Chicago. La autora también agradece a Josehp Raz por la discusión en dicha ocasión. Por la discusión de estos temas a través de años, agradece a Charles Larmore, y por los comentarios en un borrador, agradece a Daniel Brudney, Agnes Callard, Rosalind Dixon, Aziz Huq, Andrew Koppelman, Brian Leiter, Micah Lott y Henry Richardson. Finalmente, agradece extremadamente a los editores de Philosophy \& Public Affairs por sus incisivos y extremadamente valiosos comentarios.

${ }^{* * * *}$ ) Esta publicación continúa la Parte I, hecha en julio de 2016, IUS ET VERITAS 52 (julio): 370-83. Se ha mantenido la numeración original del citado para conservar la ilación del artículo original. Las notas de traductor van desde el inicio por ser otro quien traduce.

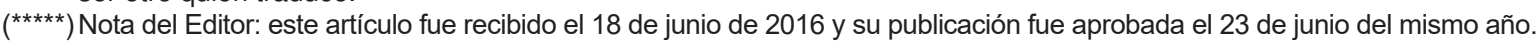


ejemplos de liberalismo político. A continuación problematiza la noción de doctrinas comprehensivas en la obra de John Rawls, pues desde la perspectiva de Nussbaum, la construcción de dicha noción acerca a Rawls a una variante de liberalismo perfeccionista que él mismo trataría de evitar. Es por ello que la propuesta de Nussbaum consiste en restaurar una noción de doctrinas comprehensivas simplemente como aquel tipo de doctrinas a las que adhieren ciudadanos razonables.

Palabras Clave: Liberalismo Perfeccionista - Liberalismo Político - Pluralismo - Isaiah Berlin - Joseph Raz - John Rawls - Charles Larmore

\begin{abstract}
In the first part of the article, the author discusses two types of liberalism from the thoughts of prominent philosophers. On the one hand, she analyzes the ideas of Isaiah Berlin and Joseph Raz as examples of perfectionist liberalism and, on the other hand, those of John Rawls and Charles Larmore as examples of political liberalism. He then discusses the notion of comprehensive doctrines in John Rawls's oeuvre, for from Nussbaum's perspective, the construction of this notion brings Rawls close to a variant of perfectionist liberalism that he himself would try to avoid. That is why Nussbaum's proposal is to restore a notion of comprehensive doctrines simply understood as those kinds of doctrines to which reasonable citizens adhere.
\end{abstract}

Keywords: Perfectionist Liberalism - Political Liberalism Pluralism - Isaiah Berlin - Joseph Raz - John Rawls - Charles Larmore

\section{Rawls: Ciudadanos Razonables, Doctrinas Comprehensivas Razonables}

Llegados a este punto, tenemos una idea sumamente abstracta, pero todavía no sabemos cómo formular principios políticos que la encarnen para sociedades en las que existen muchas doctrinas comprehensivas diferentes. Tanto Rawls como Larmore insisten en que los principios políticos de tal sociedad no son neutrales, ya que exhiben un contenido moral definido (dado en gran parte por el compromiso central con el igual respeto como valor político). El consenso entrecruzado que Rawls anhela pueda alcanzarse en última instancia es, por lo tanto, un consenso moral sustantivo, no cualquier tipo casual de superposición. De hecho, argumenta plausiblemente que ningún consenso sería estable si no descansara en nociones morales sustantivas de esta manera. Pero este ideal moral significa que no toda doctrina comprehensiva que alguien sostenga participará en el consenso entrecruzado. En este punto, tanto Rawls como Larmore introducen una noción de lo razonable para dividir a las doctrinas comprehensivas en dos grupos, aquellas que formarán parte, y aquellas que no se convertirán en participantes del esperado consenso, afirmando los principios políticos básicos de la sociedad.

Ahora debemos hacer una pausa para explorar lo que significa razonable, cuando se aplica a las doctrinas comprehensivas, ya que mucho depende de ello, y es aquí, como veremos, que se esconde una dificultad. Para Larmore, la distinción entre desacuerdos razonables y otro tipo de desacuerdos tiene una importancia considerable en la motivación de la estructura de su perspectiva. Del mismo modo, una característica importante del análisis de Rawls en $L P^{(\mathrm{NT} 1)}$ es su distinción entre doctrinas comprehensivas razonables e irrazonables. En ambos casos, hay una dificultad oculta que debemos afrontar. Comienzo con Rawls, ya que no es fácil clarificar su punto de vista. Más adelante me referiré con mayor brevedad a Larmore. En cada caso recomendaré una alternativa preferida por mi parte, que es una posible lectura del texto de Rawls, aunque probablemente no del de Larmore.

La aproximación de Rawls a las cargas de juicio enfatiza el hecho de que las personas no están de acuerdo respecto a asuntos de valores últimos y se adhieren a diferentes doctrinas comprehensivas, no simplemente por irracionalidad o descuido en el pensamiento, sino por factores que hacen que las disputas

(NT1) En lo sucesivo, Nussbaum abrevia Liberalismo Político como LP. 
Martha C. Nussbaum

entre ellos se conviertan en casos de desacuerdos razonables. Afirmar esto es reconocer "los muchos peligros que entraña el ejercicio correcto (y concienzudo) de nuestros poderes de razón y juicio en el curso ordinario de la vida política" (LP, 56). Las fuentes de desacuerdo razonable mencionadas por Rawls (páginas, 56-57) incluyen la complejidad y dificultad de la evidencia relevante; el hecho de que la evidencia por sí misma no nos dice cómo asignar peso a diferentes consideraciones; la indeterminación de conceptos centrales en casos difíciles; el hecho de que la evaluación y la ponderación de evidencia está determinada por diferentes experiencias de vida; la existencia de consideraciones normativas en ambos lados de una cuestión; y la necesidad, de cualquier sistema social, de seleccionar entre la gama completa de valores humanos que podrían ser realizados. Las personas que difieren en atención a estos factores difieren razonablemente; o, por decirlo de otra manera, los ciudadanos razonables pueden, y de hecho lo hacen, discrepar por esas razones. "Este pluralismo no es visto como un desastre, sino como el resultado natural de las actividades de la razón humana bajo instituciones libres y duraderas. Ver el pluralismo razonable como un desastre es ver el ejercicio de la razón bajo las condiciones de la propia libertad como un desastre" (pp. xxvi-xxvii). Muchas doctrinas comprehensivas pueden ser razonables en este sentido (páginas 129).

Rawls reconoce que también hay doctrinas comprehensivas irrazonables, así como desacuerdos irrazonables, doctrinas que no pueden formar parte del consenso entrecruzado porque rechazan algunas de sus ideas centrales (como la igualdad de las personas). Algunas doctrinas irrazonables pueden ser tontas e inocuas. Pero Rawls reconoce que hay doctrinas que son "no sólo irracionales sino demenciales y agresivas" (página 144). Entre estas últimas encontramos doctrinas que "rechazan una o más libertades democráticas" (página 64, n. 19). Tales doctrinas no forman parte del consenso entrecruzado. La doctrina máximamente protectora de Rawls respecto del discurso político libre sugiere que su discurso puede ser limitado solamente en la clase de emergencia que equivale a una crisis constitucional. Sin embargo, el orden constitucional habrá arraigado las libertades principales, y por lo tanto las doctrinas que proponen la eliminación de una o más de estas libertades no pueden presentarse como simples propuestas legislativas. En general, el trabajo de una sociedad liberal debe ser uno "de contención [de tales doctrinas], como la guerra y la enfermedad, para que no anulen la justicia política" (página 64 n. 19).

Es bastante claro, entonces, que la distinción entre doctrinas comprehensivas razonables e irrazonables es central para Rawls. Pero el lector se queda con varias preguntas difíciles. La primera se refiere a la manera en que Rawls articula la distinción. A lo largo del libro, incluida la sección sobre las cargas del juicio, el término razonable se emplea en un sentido ético: las personas razonables son aquellas que están dispuestas a "proponer condiciones justas de cooperación y respetarlas siempre que los demás lo hagan"(42); un segundo aspecto es la voluntad de reconocer las cargas del juicio y "aceptar sus consecuencias por el uso de la razón pública al dirigir el curso legítimo del poder político en un régimen constitucional" (página 54). (Rawls parece asumir que estas dos descripciones no se separan: las personas que están dispuestas a proponer condiciones justas de cooperación también están listas para aceptar las cargas del juicio). Este segundo aspecto es también ético: el ciudadano razonable no trata de hacer cumplir su propia doctrina comprehensiva a través del derecho, fuera del reconocimiento de las cargas del juicio y el interrelacionado respeto a sus conciudadanos. Ambos aspectos de lo razonable parecen estar estrechamente conectados con la idea de respeto, cuya centralidad en toda la empresa de Rawls es clara. En términos más generales, a través del texto, al contrastar lo razonable con lo racional, Rawls claramente emplea razonable en este sentido ético; aunque, como Samuel Freeman ha argumentado convincentemente, hay elementos epistémicos en este uso, y Rawls confía en estos "hasta cierto grado" (43). Pero eso todavía no resuelve el problema de

(42) Sobre la importancia de la noción de términos justos de cooperación para Ralws véase Larmore, "Public Reason," 391.

(43) Samuel Freeman, Rawls (New York: Routledge, 2007), 346. 
cómo Rawls emplea razonable cuando es un término aplicado a doctrinas comprehensivas, y aquí estoy de acuerdo una vez más con Freeman, quien concluye que "Rawls define doctrinas comprehensivas razonables epistémicamente, como doctrinas que son sensibles a la evidencia y poseen ciertas características teóricas."(44). Este punto es muy complejo.

Por momentos, Rawls conecta la idea de una doctrina comprehensiva razonable muy de cerca con la idea de ciudadano razonable: las doctrinas comprehensivas razonables son "las doctrinas que afirman ciudadanos razonables" (página 36). Pero luego Rawls sugiere que no busca que esta caracterización funcione como una definición, o al menos no como una definición completa de las doctrinas comprehensivas razonables. En la página 59 , habiendo asumido ya que "las personas razonables afirman sólo doctrinas comprehensivas razonables", Rawls señala que, "ahora necesitamos una definición de tales doctrinas". Su definición incluye tres rasgos, todos ellos teóricos antes que éticos. En primer lugar, una doctrina razonable es un ejercicio de razón teórica que "abarca los aspectos religiosos, filosóficos y morales más importantes de la vida humana de una manera más o menos consistente y coherente. Esta organiza y caracteriza valores reconocidos para que sean compatibles entre sí y expresa una visión inteligible del mundo". Segundo, la doctrina es también un ejercicio de la razón práctica que instruye sobre cómo ponderar valores y qué hacer cuando estos entran en conflicto. En tercer lugar, tal doctrina, aunque no necesariamente fija e inmutable, "normalmente pertenece a, o se basa en, una tradición de pensamiento y doctrina" y por lo tanto tiende a evolucionar "lentamente a la luz de lo que desde su punto de vista (...) ve [como] buenas y suficientes razones" (página 59). Rawls distingue explícitamente estas fuentes de desacuerdo de una variedad de fuentes de "desacuerdo irrazonable" (páginas 58).

Esta definición puede estar destinada en Rawls como una forma de elaborar el segundo aspecto de lo razonable en el sentido ético, a saber, "la voluntad de reconocer las cargas del juicio y aceptar sus consecuencias para el uso de la razón pública."
Sin embargo, incorpora algunos criterios teóricos bastante fuertes, aunque vagamente expresados, que no están implicados de manera obvia por esta segunda idea muy general, tal como se expuso originalmente. Los criterios teóricos plantean algunas preguntas problemáticas. Como veremos, llevan a Rawls incómodamente cerca de la posición de Raz y Berlin, añadiendo un elemento innecesario, o al menos el riesgo, de perfeccionismo a su postura.

El problema con la formulación de Rawls es que parecen haber muchas doctrinas afirmadas por ciudadanos razonables (en el sentido ético, respetuosos entre sí) que no cumplen con estos estándares teóricos más exigentes. Las visiones del mundo basadas en la astrología, la religión New Age y muchas otras perspectivas del mundo que muchos estadounidenses afirman, probablemente no satisfacen los tres criterios: algunas pueden carecer de coherencia y comprehensividad $^{(\mathrm{NT2})}$, algunas pueden ser impermeables a la evidencia (como muchos pensadores antiguos sostuvieron acerca de la astrología), algunas pueden ser demasiado fantasiosas o fragmentarias para contener lo que podríamos llamar una visión inteligible del mundo. (Mucho depende, claramente, de cómo interpretemos los criterios de Rawls.) Muchos estadounidenses sostienen doctrinas aún más extrañas: una gran proporción cree que los extraterrestres han invadido el mundo, y esto de alguna manera forma parte de su visión sobre la vida. Rawls bien podría estar dispuesto a calificar a todas esas doctrinas anticientíficas como irrazonables, dado su punto de vista que afirma que las principales conclusiones de la ciencia forman parte de la razón pública. Eso ya plantearía preguntas

(44) Freeman, 346. Sin embargo, Freeman no discute las dificultades a las que esta modificación da lugar.

(NT2) Aquí se ha traducido comprehensiveness por el neologismo comprehensividad en lugar de la palabra castellana amplitud, porque de esta manera queda más claro que a lo que Nussbaum se refiere es a doctrinas no suficientemente comprehensivas en el sentido rawlsiano. 
Martha C. Nussbaum

difíciles, ya que los ciudadanos que afirman una doctrina anticientífica todavía pueden ser razonables en el sentido ético.

Pero si miramos de cerca a algunas doctrinas clave de muchas de las principales religiones, éstas también generan problemas, que podrían pasar desapercibidos sólo porque las doctrinas nos parecen tan familiares. La doctrina cristiana de la Trinidad parece bastante sencilla; y sin embargo, como muchos filósofos cristianos enfatizan, pide al hombre cristiano que crea en una contradicción. En Paraíso ${ }^{(\mathrm{NT} 3)}$, Dante describe vívidamente esta doctrina como una manera de humillar las aspiraciones arrogantes del intelecto. Mientras Dante contempla la Trinidad y trata de pensarla racionalmente, se compara a sí mismo con un geómetra que trata de cuadrar el círculo y descubre que no puede. El intelecto humano simplemente no puede abarcar el misterio ${ }^{(45)}$.

La doctrina de la Trinidad puede ser interpretada de tal manera que se mitigue el problema, pero las variantes centrales del cristianismo, en todo caso, enfatizan la importancia de apartarse del axioma más fundamental de la razón. La doctrina de la Trinidad tampoco se trata de una cuestión que uno pueda aislar fácilmente del resto de la doctrina cristiana: es una premisa en la mayoría de los argumentos concretos que el creyente articulará o aprenderá. Sería implausible, entonces, describir esta doctrina como más o menos consistente $y$ coherente. De hecho, todo su propósito consiste en violar la consistencia y la coherencia con el fin de humillar a la razón. En otras palabras, no es sólo que desde el punto de vista de un no creyente esta doctrina clave del cristianismo parezca irracional, su irracionalidad es absolutamente clave para su significado y propósito teológico. Los cristianos modernos a menudo olvidan lo radical que es esta doctrina de la humillación del intelecto, porque están acostumbrados a la idea de la Trinidad y les resulta fácil prestarle atención sin tratar de captar algo que la mente humana no está preparada para comprender.
Otro espacio de irracionalidad en el cristianismo tradicional es la doctrina de la gracia: ello debido a que al menos en algunos relatos estándar (por ejemplo, el de Agustín), la gracia de Dios no se basa en ninguna razón en absoluto, y sin embargo debe ser reconocida como justa ${ }^{(46)}$. Una vez más, sería difícil calzar este punto de vista agustiniano en la explicación teórica de lo razonable, tal como Rawls la articula. Parece violar tanto el primer como el segundo criterio de razonabilidad (teórica) en cualquier interpretación plausible. $\mathrm{Si}$ estos problemas existen al ajustar los criterios de Rawls a la vertiente escolástica del catolicismo romano, que es la corriente más racionalista del cristianismo tradicional, existen aún más cuando contemplamos el cristianismo en sus formas protestantes y evangélicas, especialmente aquellas que piden al creyente que se aferre al texto bíblico, que sería muy inverosímil describir como un todo coherente y consistente. Más aún, los cristianos fundamentalistas (a diferencia de los creyentes en otras épocas) no proponen estrategias de interpretación no literal que suavicen o eliminen las inconsistencias.

El judaísmo tradicional, aunque en cierto sentido más racionalista que el cristianismo, contiene igualmente la exigencia de aceptar un misterio que, en principio, no puede ser comprendido por la razón. El final del libro de Job, por ejemplo, contiene un vívido repudio de las aspiraciones del racionalismo helénico, que ha dado lugar a una prominente vertiente mística en el judaísmo, ejemplificada por Gershom Scholem y los rabinos jasídicos. Por

(NT3) Como se sabe, "Paraíso" (Paradiso) es el tercer conjunto de cánticos de la Divina Comedia de Dante Alighieri. Al mismo le anteceden los conjuntos Ilamados "Infierno" y "Purgatorio". Véase la excelente edición de Alianza Editorial (Versión poética de Abilio Echeverría).

(45) Paraíso, canto 23; compárese con Purgatorio, canto 31, líneas 13-21, donde Dante se compara a sí mismo con un arco demasiado tenso y que por lo tanto se rompe, empleando la metáfora aristotélica de la aspiración intelectual para mostrar que tal aspiración por comprender debe ser humillada ante el amor cristiano.

(46) Véase la interpretación del Ad Simplicianum de Diversis Quaetionibus de Agustín de Hipona propuesta por Peter (Berkeley y Los Angeles: University of California Press, 1967), 155 y siguientes. 
otra parte, muchas formas de judaísmo contienen un principio de autonomía que los hace funcionar en contra de la segunda doctrina de Rawls: no hay instrucciones previas para los casos difíciles, precisamente porque cada persona debe averiguar qué hacer por sí misma: la ley no está en el cielo, sino en la tierra (Deuteronomio 30: 12-14). El judaísmo reformista ha incrementado el alcance de ese principio, de modo que la autonomía supera por completo al dogma, y podríamos decir que al final el judaísmo reformista no tiene doctrinas (quizás ni siquiera teísmo, aunque esto es discutido), sólo la idea central de la ley moral, que cada creyente debe interpretar y aplicar al mundo a su manera. Para el judaísmo reformista, si la doctrina religiosa provee de alguna estructura teórica, con ello parece vulnerar la autonomía ${ }^{(47)}$.Esta todavía parece una doctrina comprehensiva, pero no cuenta como razonable, según la definición de Rawls. Ni siquiera instruye a los creyentes para desarrollar soluciones consistentes y coherentes propias, tales que satisfagan el primer y segundo criterio de Rawls; y rechaza activamente el tercer criterio (basado en la tradición), quitando cualquier peso moral a la tradición.

Una podría multiplicar los ejemplos. Lo que está claro, entonces, es que Rawls ha introducido una gran dificultad al definir doctrinas razonables en términos de estos criterios teóricos, una dificultad que pertenece no sólo a las doctrinas que él podría estar dispuesto a menospreciar como irrazonables (aunque creo que no debería hacerlo), sino también a doctrinas que son centrales para su motivación y propósito. Más aún, su definición parece ir en contra de una de las ideas centrales del texto, la idea de respeto por los ciudadanos razonables. Mientras las personas sean razonables en sentido ético, ¿por qué la concepción política las debería denigrar porque creen en la astrología, en los cristales o en la Trinidad? ¿Por qué no dejarlos, a ellos y a sus creencias, en paz? De hecho, la interpretación teórica de lo razonable, aunque no equivalente a la posición de Raz y Berlin, se acerca demasiado a la misma para sentirnos cómodos, permitiendo la denigración pública de un grupo de doctrinas comprehensivas que, desde el punto de vista de los objetivos éticos de la concepción política, no son problemáticas.
Es revelador, y un signo de la profundidad del problema, que un intérprete que trabajó especialmente cerca de Rawls, en una conferencia cuyo objetivo era describir claramente las ideas centrales de $L P$, atribuyera a Rawls la doctrina que acabo de sugerir debiera sostener:

Una doctrina comprehensiva razonable puede ser irracional, puedes ser como Tertuliano y decir: "Yo creo porque es absurdo". Todo lo que una doctrina comprehensiva tiene que hacer para ser razonable es abrazar una concepción política liberal. Pero fuera de ello puede sostener cualquier cosa que quiera ${ }^{(48)}$.

Burton Dreben, que reconstruye a Rawls con fidelidad en cada otro tema, hasta donde puedo ver, claramente se encuentra errado respecto de algunas partes clave del texto en este tema ( $y$ el fidedigno estudio del texto por parte de Freeman coincide). Pero no está errado, sugiero, respecto del espíritu más profundo del proyecto de Rawls y la centralidad de la noción de respeto en él. Tal vez Rawls realmente debería haber utilizado la noción de ciudadano razonable para definir las doctrinas comprehensivas razonables: las doctrinas razonables son sólo aquellas doctrinas (aunque fragmentarias o afectadas por inconsistencia) que los ciudadanos razonables afirman. Las cargas del juicio podrían entonces entrar en el pensamiento de tales ciudadanos cuando piensan en por qué no deben insistir en la verdad de su doctrina en el ámbito público. Pero eso es suficiente para ellos: los ciudadanos razonables no deben entrar a la lógica de mirar por encima de los hombros de sus conciudadanos para preguntarse si sus doctrinas contienen un

(47) Para una discusión sobre algunos textos históricos fundamentales véase Martha Nussbaum, "Judaism and the Love of Reason," Philosophy, Feminism, Faith, ed. Marya Bower y Ruth Groenhout (Bloomington: Indiana University Press, 2003), 9-39.

(48) Burton Dreben, "On Rawls and Political Liberalism," The Cambridge Companion to Rawls, ed. Samuel Freeman (New York: Cambridge University Press, 2003) 326. 
Martha C. Nussbaum

ejercicio aceptablemente comprehensivo y coherente de razón teórica. Tal escrutinio, además de invitar al tu quoque que el New Ager o el aficionado a la astrología podría dirigir a un cristiano corriente, es una especie de interferencia que no tiene lugar en un liberalismo político respetuoso.

Por supuesto, es bastante claro que los ciudadanos de la Sociedad Bien Ordenada de Rawls serán bienvenidos para criticar las doctrinas comprehensivas de otras personas, religiosas o seculares, en las muchas discusiones que tienen lugar dentro de la cultura de fondo (sociedad civil e interacciones personales informales). Ni siquiera tienen el deber político de ser civilizados cuando lo hacen; el deber de civilidad de Rawls sólo se refiere a las discusiones sobre elementos constitucionales esenciales y asuntos de justicia básica que tienen lugar dentro del marco de ciertos roles políticos clave (por ejemplo, los de juez, legislador y votante). Así, los ciudadanos tienen el deber moral de no votar en contra de alguien por el hecho de que no les guste la religión de esa persona, pero incluso ese es un deber moral no ejecutable. Lo que Rawls desea descartar es que el Estado haga declaraciones (o incorpore principios) que denigren una religión o doctrina y que prefieran otra, siempre y cuando la doctrina en cuestión sea razonable. Las doctrinas irrazonables pueden ser denigradas, y al Estado se le permite, y tal vez se le requiere, incorporar principios que denigran a dichas doctrinas. Lo que estoy diciendo aquí es que esto está bien, siempre y cuando la definición de lo razonable sea la ética, lo que autoriza al Estado a criticar, por ejemplo, a doctrinas que creen en la esclavitud o la subordinación política de las mujeres. Lo que parece muy problemático, sin embargo, es otorgar licencia al Estado para que critique doctrinas que son irrazonables en el sentido teórico. Si quiero creer algo tonto, o subordinar mi juicio al de alguna autoridad irracional, no es asunto de una sociedad pluralista declarar que soy en cualquier sentido inferior por así hacerlo.

¿Por qué incluyó Rawls los criterios teóricos en su definición de la noción de razonabilidad? Como todos los puntos de Rawls sobre los cuales uno podría pensar que está equivocado, éste tiene profundas raíces en su pensamiento y buenos argumentos en su favor. Rawls piensa que el tipo de respeto del que depende la democracia liberal requiere, o al menos le resulta muy útil, distinguir entre doctrinas que son simplemente tontas o de algún modo obviamente irracionales y doctrinas que no lo son; los titulares de doctrinas de este último grupo no están de acuerdo debido a las cargas del juicio, problemas de razón comunes a todos los seres humanos en condiciones de libertad y, por lo tanto, problemas que no comprometen el respeto mutuo ${ }^{(49)}$. Los titulares de doctrinas en este último grupo se sentirán de manera diferente, sugiere Rawls, acerca de los poseedores de doctrinas en el primer grupo: pensarán que si estas personas hubieran corregido los errores en su razonamiento, mantendrían las doctrinas que nosotros mantenemos. ( $¿ Y$ entonces qué: se sentirían inclinados a no tratarlos con igual respeto?) Rawls no dedica mucho espacio de discusión al gran número de personas reales, razonables en el sentido ético, que sostienen doctrinas que él mismo probablemente clasificaría en esta categoría, como las creencias New Age o la astrología. Tal vez si discutiera estos casos estaría dispuesto a mantener que los ciudadanos que los afirman son irrazonables, apegándose a los criterios teóricos por él propuestos; pero se podría sentir que tal juicio muestra demasiado poco respeto por los ciudadanos razonables (en el sentido ético). Lo que pone en peligro todo el proyecto rawlsiano de ofrecer criterios teóricos para la razonabilidad, sin embargo, hasta donde puedo ver, es el hecho de que las principales religiones, sus casos centrales y aquellas cuyos adherentes más quiere persuadir, fracasan en cumplir con los criterios, y lo hacen por razones que, en el caso del cristianismo, se profundizan:

(49) De manera similar, la idea de que es muy difícil arribar a una visión correcta en tales asuntos, incluso empleando la propia razón de la mejor manera posible resulta fundamental para al menos una de las líneas de defensa de Locke sobre la tolerancia. 


\section{Liberalismo Perfeccionista y Liberalismo Político (Parte II) Perfectionist Liberalism and Political Liberalism (Part II)}

un repudio de la razón teórica que está en el centro de la explicación de la fe de esa religión, al menos en algunos casos centrales.

Si Rawls adoptara la sugerencia que he planteado, probablemente necesitaría articular su exposición de las cargas del juicio como una serie de observaciones históricas o sociológicas sobre la modernidad, más que como una base para la distinción normativa entre doctrinas razonables e irrazonables ${ }^{(50)}$. Podría decir simplemente, entonces, que todos debemos reconocer que el desacuerdo es a veces el resultado de instituciones libres y que todos debemos reconocer que podemos participar en una cooperación social respetuosa sin llegar a un acuerdo sobre cuestiones religiosas ${ }^{(51)}$. Este sería un alto precio a pagar para Rawls, en términos de las ambiciones teóricas del programa que él y Charles Larmore comparten, porque dejaría caer la distinción fundamental entre el mero error y las fuentes de desacuerdo más dignas de respeto. Yo misma considero que no es un precio demasiado alto: porque al pagarlo compramos una noción más amplia e inclusiva de respeto. Simplemente no parece correcto que los ciudadanos busquen las religiones de otros ciudadanos y pregunten cuán razonables son, siempre que las doctrinas que poseen sean razonables en el sentido ético que está implicado en la concepción política pública.

Rawls parece dar un paso decisivo en la dirección que yo defiendo en la sección en que discute el consenso entrecruzado: porque aquí él indica que una manera en que el movimiento desde un mero modus vivendi hacia un consenso entrecruzado tiene lugar es a través del hecho de que los ciudadanos tienen usualmente "una cierta soltura en [sus] perspectivas comprehensivas" (página 159): "Las doctrinas religiosas, filosóficas y morales de la mayoría de gente no son vistas por estas como totalmente generales y comprehensivas" (página 160), y este hecho permite el deslizamiento, a medida que los ciudadanos vienen a adoptar la concepción política, a menudo "sin ver ninguna conexión particular, de un modo $u$ otro, entre esos principios y sus otros puntos de vista" (página 160). Estas observaciones importantes no se aplican de nuevo al relato de las cargas del juicio o a la distinción entre doctrinas comprehensivas razonables e irrazonables, pero al menos indican que Rawls está dispuesto a interpretar sus criterios teóricos de manera muy vaga. En cualquier caso, los lectores deben resolver esta cuestión por sí mismos.

El texto de Larmore contiene un problema similar, que trataré más brevemente. Al igual que Rawls, Larmore piensa claramente que es importante distinguir los desacuerdos razonables de otros tipos de desacuerdos ${ }^{(52)}$. Él ofrece una aproximación de las cargas de la razón que es similar a la de Rawls, enumerando una variedad de factores que pueden impedir que la gente llegue a un acuerdo. Señala que todavía no tenemos una explicación de por qué el desacuerdo en cuestiones de valor deba ser tan penetrante, mientras que el desacuerdo científico es menos omnipresente. Dice que no tiene una explicación para esta diferencia ${ }^{(53)}$.

(50) Y por ello no es tampoco claro si la aproximación de personas razonables, correspondientemente, necesitaría ser revisada: podría ser que sólo sobreviviera la condición que tiene que ver condiciones justas de cooperación, y la que tiene que ver con las cargas del juicio fuese desechada. Estoy agradecida con Erin Kelly por iluminar la discusión en este punto.

(51) Rawls parece tomar esta línea de análisis en IPRR, su última intervención sobre esta cuestión: véase 573-74; una pluralidad de doctrinas en conflicto es el resultado normal de una cultura de instituciones libres, y "[los] ciudadanos se dan cuenta de que no pueden llegar a un acuerdo o siquiera acercarse a la mutua comprensión sobre la base de sus doctrinas comprehensivas irreconciliables."

(52) Para Larmore, esta es la distinción fundamental; a diferencia de Rawls, no centra la atención teórica en la distinción entre doctrinas comprehensivas razonables e irrazonables, aunque probablemente consideraría esta como una distinción estrechamente relacionada.

(53) Larmore, "Pluralism and Reasonable Disagreement," 171. En su artículo de 2005 titulado "Respect for Persons" (citado en la nota 34, publicada en la parte I de este artículo, IUS ET VERITAS 52, 380), Larmore afirma explícitamente que para él razonable, aplicado a las doctrinas comprehensivas, no es una noción que fluya directamente de la noción de igual respeto; 
Martha C. Nussbaum

Pero insiste en que es importante distinguir el desacuerdo razonable del escepticismo: las partes en desacuerdo pueden ser capaces de ofrecer razones para sus opiniones, y esas razones pueden satisfacer un alto estándar. No es porque la gente no tenga buenos argumentos para sus puntos de vista que no están de acuerdo. En particular, Larmore está decidido a rechazar la idea de que la gente se adhiera a sus opiniones ante el desacuerdo debido a la fe. "Nuestra lealtad [a nuestro parecer] puede ser mucho más que una cuestión de fe"(54). Poco después, sostiene que no necesitamos considerar estas fidelidades. Por lo tanto, parecería que un desacuerdo cuenta como razonable para Larmore sólo si ambas partes basan su lealtad en argumentos y no simplemente en la fe.

Creo que esta exigencia de un tipo particular de fundamento para una visión es irrespetuosa para los ciudadanos religiosos que piensan que la fe es una muy buena base para sus puntos de vista, y de hecho la mejor base posible. Al tratar de articular una versión del liberalismo que no se base en controvertidas doctrinas metafísicas o epistemológicas, él importa una doctrina de este tipo en la misma afirmación de la visión. La teoría de Rawls está por lo menos dividida en este asunto; Larmore parece no estar en absoluto dividido. Piensa claramente que la fe es una fuente menor para una visión, frente a un argumento razonado, y parece no pensar que esto sea un problema para una visión política que desea mostrar un respeto igual para todas las personas.

Mi solución a este problema es que recordemos que el respeto en el liberalismo político es, ante todo, respeto a las personas, no respeto por las doctrinas que sostienen, el fundamento de esas doctrinas o cualquier otra cosa sobre ellas. Es porque respetamos a las personas que pensamos que sus doctrinas comprehensivas merecen espacio para desarrollarse y merecen un trato respetuoso y no derogatorio por parte del gobierno (sea cual fuere el tratamiento que reciben por parte de los ciudadanos en la cultura de fondo).
Para un funcionario público en un rol de liderazgo, decir "la doctrina de $X$ no está tan bien fundamentada como la de $Y$ " es, inevitablemente, denigrar a $\mathrm{X}$, y queremos que nuestros principios políticos muestren el mismo respeto por $\mathrm{X}$ que por $\mathrm{Y}$. Debemos, entonces, evitar definir razonable de una manera tal que denigre los fundamentos de las doctrinas de algunas personas: hacer lo contrario es violar el deber de abstención frente a las doctrinas epistemológica y metafísicamente controversiales, deber sobre el que el liberalismo político nos pide con razón insistir.

Por lo tanto, seguiremos con la definición ética de razonable. Un ciudadano razonable es aquel que respeta a otros ciudadanos como iguales. Una doctrina comprehensiva razonable es aquella adoptada por un ciudadano razonable, es decir, que incluye un compromiso serio con el valor del respeto igual a las personas como valor político. Más allá de eso, es simplemente impertinente que el Estado o sus agentes investiguen la base de la adhesión religiosa de la gente. Ya sea basada en la tradición, en la autoridad, en argumentos, en la fe o basada en nada más que su atractivo, una doctrina religiosa merece ser llamada razonable si y sólo si es el tipo de doctrina que puede ser adoptada por un ciudadano razonable. El objeto del respeto es la persona y las facultades de la persona (la conciencia, por ejemplo). No requerimos decir nada sobre las diferencias entre las doctrinas comprehensivas (más allá de descartar algunas como incompatibles con el igual respeto), y ciertamente debemos evitar una clasificación del tipo que Larmore, y a veces Rawls, parecen sugerir.

él arroja dudas sobre esta clase de visión, señalando que, "naturalmente, poco se logra mediante maniobras definitorias." Su propia definición de razonable es bastante abstracta, involucrando "el ejercicio de las capacidades básicas de la razón y conversación de buena fe con los demás." Una aproximación anterior es "pensar y conversar de buena fe y aplicar, de la mejor manera posible, las capacidades generales de la razón que pertenecen a todos los ámbitos de indagación”. De este modo, parecería favorecer una definición al menos parcialmente teórica y sólo mínimamente ética.

(54) Larmore, "Pluralism and Reasonable Disagreement," 173. 
Liberalismo Perfeccionista y Liberalismo Político (Parte II) Perfectionist Liberalism and Political Liberalism (Part II)

\section{En defensa del Liberalismo Político}

Consideremos las muchas visiones religiosas y seculares de la vida que actualmente existen en las sociedades. Muchas, si no la mayoría, no pueden aceptar la idea de Raz de que la autonomía, entendida como la entiende Raz, deba ser un ideal moral. Algunas religiones permiten a sus adherentes más autonomía y otras menos; pero muy pocas la valoran como lo hace Raz. (Por otra parte, como hemos dicho, pocas religiones aceptan el pluralismo moral de Berlin, una opinión que Raz piensa presupuesta por la moralidad de la autonomía). En cuanto a las visiones seculares de la buena vida, la mayoría de ellas tampoco son muy pluralistas. Muchos marxistas no piensan que los puntos de vista no marxistas deban ser tolerados, aunque este punto es discutido; ciertamente un marxista serio no puede conceder que las principales religiones y las doctrinas éticas comprehensivas de la moral burguesa son objetivamente verdaderas ${ }^{(55)}$. Los utilitaristas típicamente sostienen que las perspectivas kantianas y aristotélicas no son ni siquiera aceptables, y ciertamente no las creen objetivamente verdaderas. Muchos titulares de perspectivas seculares no piensan en las opiniones religiosas como aceptables, y ciertamente no las consideran verdaderas. Lo mismo ocurre con la visión que los creyentes religiosos adoptan respecto de las doctrinas seculares.

Raz, entonces, y claramente también Berlin, quieren construir la sociedad liberal partiendo de un conjunto de puntos de vista que prácticamente ninguno de sus miembros realmente sostiene. En el caso de Berlin, uno puede ver frente a qué está reaccionando: el peligro para la libertad humana que proviene del dogmatismo excesivo respecto del propio ideal. Pero no parece darse cuenta de que su propia alternativa pluralista, adoptada como principio político, tendría consecuencias igualmente peligrosas. En la sección titulada "Sobre la Religión Civil" de El Contrato Social, Rousseau crea una religión estatal que contiene algo como el pluralismo de Berlin, en la forma de una doctrina de tolerancia teológica: no se puede sostener que una religión es correcta y las demás incorrectas. Rousseau cree que la paz civil requiere tal creencia teológica, y puede ser que Berlin sostenga algo como esto. Ambos, al servicio de la tolerancia, tal como la entienden, requieren de todos los ciudadanos algo que prácticamente ninguno puede creer sin abandonar su religión. Rousseau sabe muy bien que su religión civil resultará inaceptable para los católicos romanos y para muchas, si no la mayoría de las variedades del protestantismo. Está dispuesto a desterrar a los adherentes de tales puntos de vista si no los dejan ceder a favor de la religión civil. Raz y Berlin no llegan a hacer una propuesta tan draconiana, pero sí insisten en construir el Estado sobre principios que una gran parte de sus ciudadanos no pueden aceptar.

Este es claramente un problema estratégico. Es difícil ver cómo un liberalismo de este tipo podría permanecer estable, a menos que los ciudadanos religiosos realmente hagan algo como lo que Rousseau quiere, dejando ceder su religión a favor de la doctrina del Estado liberal. No es sorprendente que Rousseau previera un papel importante para el destierro en su sociedad. El problema, sin embargo, es aún más grave: es un problema de respeto. Cuando las instituciones que penetrantemente gobiernan tu vida están construidas sobre la base de una visión que a toda conciencia no puedes aceptar, eso significa que te encuentras, de hecho, en una posición de ciudadanía de segunda clase. Incluso si eres tolerado (y no es demasiado claro a partir del artículo de Raz hasta qué punto las grandes religiones serían toleradas), el gobierno declarará, cada día, que una visión diferente, incompatible con la tuya, es la correcta, y que la tuya es incorrecta. Más aún, como explicó Raz explícitamente en la discusión de su artículo(56), el gobierno tendrá licencia

(55) ¿Es el marxismo una doctrina comprehensiva razonable en el sentido de Rawls? No si se requiere respaldar el uso legítimo de la violencia y la suspensión de las libertades políticas; pero hay versiones del marxismo, tanto en filosofía (G. A. Cohen, Jon Elster) como en política (los partidos marxistas de la India y de algunas partes de Europa) que parecen calificar como razonables.

(56) Law-Philosophy Workshop, The University of Chicago, 2008. Incluso cuando Raz no señala esto en MF, ello parece ser una consecuencia natural de la importancia teórica que le da a la aceptación general de estas visiones. 
Martha C. Nussbaum

para tratar de convertirte a la visión correcta. Esto es lo que yo llamaría subordinación expresiva, la misma que consiste en ser clasificado públicamente por debajo de los demás ${ }^{(57)}$.

La subordinación expresiva es una forma de establecimiento establishment $t^{\left(\mathrm{NT}^{4}\right)}$ religioso. El hecho de que el punto de vista de Raz sea secular no marca diferencia alguna en lo referente a esta conclusión. Y es erróneo por la razón de que el establishment religioso siempre está equivocado: comete una ofensa contra la igualdad de los ciudadanos. Les dice, para citar a James Madison, que no todos entran en la arena pública "en igualdad de condiciones"(58). Esta conclusión aparentemente no preocupa a Raz: si no aceptan el hecho del pluralismo y el ideal de autonomía, está bien tratarlos de manera desigual. Pero esto me preocupa, al igual que preocupaba a Larmore y a Rawls. Preocupa porque muchas personas piensan que el tipo de liberalismo comprehensivo de Raz es la única forma viable de liberalismo, y también piensan que el liberalismo no es neutral en cuanto a la buena vida, sino que es una forma de religión por derecho propio.

Pero el liberalismo de Raz, como hemos visto, no es la única forma de liberalismo. Pues uno puede desarrollar una forma de liberalismo que parta de la idea del igual respeto para las personas. Uno razona entonces que el igual respeto no requiere establecer a ninguna de las formas de vida disponibles como ideal, sino que, en su lugar, requiere prescindir de cualquier clasificación de vidas. Al ver cómo, en condiciones de libertad, la gente no está de acuerdo respecto de valores, debemos mostrar respeto por esos desacuerdos razonables basando nuestros principios políticos en una visión fina y abstemia, tal que se abstenga de controversias metafísicas, epistemológicas y pretensiones éticas comprehensivas.

El punto de vista tendrá claramente un contenido moral: pero la esperanza es que su contenido moral sea aceptable para todas las principales doctrinas comprehensivas, una especie de módulo, como sostiene Rawls, que todos puedan atribuir a sus propias opiniones de vida. Es, por lo tanto, objeto de un consenso entrecruzado entre todas las principales perspectivas de vida. Esta esperanza sólo puede realizarse si (al hablar desde un rol político) evitamos cuidadosamente hacer afirmaciones perfeccionistas de la manera que Raz hace, o incluso, pienso, reivindicaciones acerca de razones, a la manera que Larmore $y$, a veces, Rawls hacen. No diremos que la autonomía hace que las vidas sean mejores en general, y no adoptaremos un pluralismo moral. Tampoco diremos que es mejor ofrecer argumentos para un punto de vista que sostenerlo mediante la fe. Pero mostraremos respeto a los ciudadanos creando y protegiendo espacios en los que puedan vivir según sus propios puntos de vista.

Rawls y yo misma insistimos en que hay una noción cercana a la de autonomía que debe figurar en esta perspectiva: para que la verdadera libertad de vivir de acuerdo con la propia opinión se de en la práctica, también se requiere proteger los espacios en los que las personas pueden abandonar una visión y optar por otra, y también los espacios en los que los niños aprenden acerca de las opciones, de forma tal que ellos puedan realmente vivir sus propias vidas. Este tipo de cosas es a las que Rawls Ilama "autonomía política"(59). No es, sin embargo, lo mismo que la autonomía de Raz, porque no hay ninguna declaración hecha por el Estado en el sentido de que

(57) Por supuesto, desde mi punto de vista, ciudadanos individuales y grupos de ciudadanos en la cultura de fondo gozarán de libertad para tratar de convertir a otros a su punto de vista: la fobia a la conversión que ha llevado a algunos Estados indios a restringir el proselitismo no tiene lugar en el liberalismo político El punto es más bien que el gobierno no puede ser el agente de este proceso sin establecer una jerarquía.

(NT4) El sentido de la palabra establishment en esta oración corresponde al de la imposición de una religión por parte de un grupo particular que dirige las riendas sociales.

(58) Madison, "Memorial and Remonstrance Against Religious Assessments," 1785, Religion and the Constitution, $2^{\circ}$ ed., eds. Michael McConnell, John H. Garvey, y Thomas C. Berg, (New York: Aspen, 2006), 50.

(59) LP, páginas xliv-xlv 


\section{Liberalismo Perfeccionista y Liberalismo Político (Parte II) Perfectionist Liberalism and Political Liberalism (Part II)}

las vidas vividas bajo la dirección propia son mejores que las vidas vividas en sumisión a alguna forma de autoridad religiosa, cultural o militar ${ }^{(60)}$. Por supuesto, en el Estado de Rawls ninguna autoridad cultural puede coaccionar a las personas, y estas siempre deben ser libres para disfrutar de sus derechos plenamente iguales como ciudadanos, incluida la libre elección de la ocupación y la libertad de religión. Pero el católico romano, o el miembro de la antigua orden Amish, todavía pueden sentir que la visión política, al proteger los espacios en los que ellos reclaman autoridad, los respeta y no los denigra, como no sería el caso con la variante comprehensiva de autonomía de Raz.

La autonomía política no es totalmente neutral: tiene una visión definida acerca de los ingredientes de una buena vida política, incluyendo el respeto a la deliberación y el intercambio público de razones. En ese sentido, no apunta al tipo de política que algunas de las doctrinas comprehensivas podrían querer para sí mismas, si quisieran establecer una teocracia sin pluralismo interno. Tal, sin embargo, no es la condición de la modernidad, y los creyentes son conscientes de ello. Dado que comparten una vida política común con otros con quienes difieren, pueden ver a los requisitos de la autonomía política como respetuosos de sus creencias, entendiendo a lo político como un espacio de diferencias gobernado por el respeto mutuo, mientras que no podían aceptar una autonomía del tipo defendido por Raz, prescrita como un valor comprehensivo. Podría ser que los ciudadanos que crezcan en un contexto de autonomía política puedan con el tiempo aspirar a la autonomía por el resto de sus vidas: así, como Rawls menciona, es posible que su ideal ejerza más presión sobre algunas doctrinas que sobre otras. Pero aquí debemos estar de acuerdo con Rawls: demostrar que todas las doctrinas tendrán igualdad de condiciones para ganar adherentes en el tiempo no demuestra que la visión política sea una que respete a los ciudadanos como iguales ${ }^{(61)}$. (Además, la especulación sociológico-psicológica podría resultar falsa: la autonomía política puede hacer que al menos algunas personas anhelen el control y la seguridad intelectual en otras partes de su vida).

Se ha hecho evidente ahora que las religiones principales pueden de hecho aceptar el liberalismo político de corte rawlsiano, aunque no pueden aceptar el liberalismo perfeccionista de Raz. Los católicos romanos, por ejemplo, pueden estar de acuerdo con Rawls en que debemos sustentar la tolerancia en una perspectiva de igual respeto por las personas. Tal persona seguirá pensando que su religión es verdadera y otras falsas; pero el respeto a las personas requiere proteger el espacio en el que cada uno vive bajo sus propias luces. Así obtenemos una amplia tolerancia, pero sin subordinación expresiva.

Como hemos visto, el liberalismo político no evita afirmar que algunas doctrinas éticas y religiosas son inaceptables. Ello es así porque sus principios políticos tienen un contenido moral, destacando la igualdad de los ciudadanos y la importancia del igual respeto. Tales ideas estarán profundamente arraigadas en la constitución de una sociedad. Por lo tanto, el proponente de la esclavitud o de la jerarquía de género no obtendrá el mismo trato en esa sociedad: la vida que quiere llevar ofende normas constitucionales fundamentales, por lo que tendría que enmendar la constitución para poder vivirla. No obstante, Rawls sostiene que esa persona gozará de una amplia libertad para hablar y actuar, siempre y cuando no vulnere los derechos de los demás ${ }^{(62)}$.

(60) Ningún Estado sostiene esto en realidad, porque cada Estado requiere de defensa miliar, y presumiblemente Raz no negaría ello. Su Estado, entonces, debería decir, "está bien subordinar tu autonomía al servicio de tu país, pero no a la autoridad religiosa", un enunciado incluso más problemático que una condena general de todas las formas de vida no autónomas.

(61) Véase LP, 199: "El liberalismo político está injustamente sesgado en contra de ciertas concepciones comprehensivas sólo si, por ejemplo, los individuos individualistas pueden perdurar en una sociedad liberal, o predomina que asociaciones que afirman valores de religión o comunidad no pueden florecer y, además, las condiciones que conducen a este resultado son injustas, en vista de circunstancias presentes y previsibles."

(62) LP, 340-56. En tal caso, la persona sería irrazonable en el sentido ético, como lo sería su doctrina; pero el Estado no adoptaría ninguna acción, dado que esta persona no estaría violando los derechos de otros o causando una amenaza de transgresión. 
Martha C. Nussbaum

¿Por qué uno preferiría la perspectiva de Raz a la de Rawls? Una razón, que parece ser la de Berlin y Raz, consiste en una profunda convicción de que su ideal moral es correcto e importante, y que cualquier buena sociedad debe reconocer este hecho. He argumentado que dichos autores pagan un precio demasiado alto por lo que podríamos llamar irónicamente su búsqueda del ideal: el precio de la denigración y la subordinación expresiva de muchos ciudadanos que están dispuestos a vivir con los demás en términos de igualdad y reciprocidad.

Otra razón para preferir el perfeccionismo (aunque no es la de Berlin y Raz) podría consistir en un profundo racionalismo. Para algunas personas, y parece que tanto Kant como Mill estaban entre estas ${ }^{(63)}$, la cuestión principal que ha marchado mal con la mayoría de las sociedades es que estas han basado sus principios políticos en una deferencia irracional a la tradición o la autoridad; lo correcto para corregir esta tendencia perniciosa consiste en fundamentar los principios políticos en un racionalismo comprehensivo. Para tales personas parece intolerable que el Estado se limite a decir que la argumentación racional es central en la vida política: seguramente la fe es siempre y en todas partes peor que la argumentación. Tales personas reconocerán que la política rawlsiana pone a la evidencia y a la argumentación racional en el asiento de conductor del ámbito político ${ }^{(64)}$ : pero el fracaso de recomendar a la razón sobre la fe más globalmente parece un gran fracaso. ¿Puede realmente ser el caso, por ejemplo, que los maestros en las escuelas públicas (que son por lo tanto agentes del gobierno) puedan recomendar la argumentación sobre la fe solamente para los propósitos de la ciudadanía, y no como la mejor manera de abordar los problemas de la vida en general? Esto parece intolerable para el racionalista.
He estado enfrentando a este oponente a lo largo del artículo, señalando la conexión entre igual respeto por las personas, por parte del Estado, y una negativa a adoptar cualquier doctrina comprehensiva. Y creo que la respuesta a la indignada pregunta es sí: los maestros de escuelas públicas no deben decir que la argumentación es mejor que la fe como una forma general de resolver todos los problemas de la vida ${ }^{(65)}$. Decir ello es denigrar a los estudiantes que son miembros de religiones no racionalistas. Ciertamente pueden decir que en contextos en los que los ciudadanos de muchas opiniones diferentes discuten sobre cuestiones fundamentales, la argumentación racional es crucial. También pueden recomendarla como parte integrante de una empresa en particular, como la prueba científica. Pero ellos no deben decir: "Vive tu vida guiado por la razón y no por la fe." Los racionalistas seculares no estarían de acuerdo, pero no estoy segura de cómo vislumbrar la siguiente etapa de la discrepancia aquí.

Hay otro argumento que nos lleva de nuevo al liberalismo comprehensivo, y creo que es más fuerte que el argumento racionalista. Se podría creer razonablemente, y argumentar, que la mayoría de las opiniones en la mayoría de las sociedades son racistas, sexistas o jerárquicas de alguna u otra manera, y que sólo una perspectiva comprehensiva perfeccionista, aceptada como base del

(63) Aunque, una vez más, aquí las controversias exegéticas acerca de la interpretación de Kant y Mill son irrelevantes para mi argumento.

(64) Sobre la delicada cuestión de cómo la concepción política avanzará una norma de objetividad sin llegar a ser una doctrina comprehensiva, véase Nussbaum, "Political Objectivity," New Literary History 32 (2001): 883-906, donde se interpreta y defiende la postura de Rawls.

(65) No está claro si los deberes rawlsianos de civilidad se aplican a tales personas: se podría argumentar que lo hacen; dada la influencia omnipresente de la educación pública sobre toda la vida como ciudadano, las escuelas forman parte de la estructura básica. Pero incluso si uno se resiste a esta idea y, por lo tanto, sostiene que es moralmente permisible que los maestros hagan declaraciones defendiendo el racionalismo comprehensivo, se debe insistir en que el maestro muestre que la nación en la que los alumnos y maestros viven no se basa en la verdad del racionalismo comprehensivo, de modo que el maestro simplemente discuta su propia doctrina comprehensiva, no desde el punto de vista de los valores públicos. 


\section{Liberalismo Perfeccionista y Liberalismo Político (Parte II) Perfectionist Liberalism and Political Liberalism (Part II)}

Estado, podría realmente deshacerse de la influencia política funesta de tales opiniones. El objetor trataría de demostrar que las visiones jerárquicas son típicamente irracionales, basadas en estereotipos que no soportan a la luz de la argumentación racional. Florecen cuando se les priva de esa luz, pero se marchitan cuando son expuestas a ella. Así, en las sociedades que promueven la tradición y la autoridad sobre la razón, es probable que dichas doctrinas demuestren ser fuertes, mientras que una sociedad racionalista comprehensiva puede combatirlas eficazmente.

Este punto de vista, al parecer, fue mantenido por John Stuart Mill. En The Subjection of Women, él argumenta que los estereotipos sobre la diferencia de género que mantienen a las mujeres subordinadas simplemente no resistirán la prueba de la evidencia y la argumentación. Así se marchitarán cuando estén expuestos a la discusión. Mill sabe que será bastante duro para el argumento prevalecer sobre la opinión tradicional; pero luego deplora el hecho de que su sociedad está perdiendo la fe en la razón que caracterizó a la sociedad del siglo XVIII. "Para la apoteosis de la Razón", escribe, "hemos sustituido la del Instinto; y llamamos a todo el instinto que encontramos en nosotros mismos y para el cual no podemos trazar ningún fundamento racional"(66). Así, aunque se construyan buenos argumentos contra los estereotipos, no lograrán tener una audiencia en una cultura que generalmente desestima la argumentación ${ }^{(67)}$.
La última Susan Moller Okin, distinguida teórica política feminista y editora de Subjection de J.S. Mill, rechazó el liberalismo político de Rawls por estas razones: pensaba que la mayoría de las religiones y las culturas tradicionales eran sexistas hasta el núcleo, por lo que la única manera de progresar era acabar con ellas, en la medida de lo posible, mediante la persuasión pública(68). Dado que la libertad de expresión no sería suprimida, la única forma de desestimar públicamente a la religión parecería ser el respaldo a una doctrina comprehensiva perfeccionista que incluya, en primer lugar, la igualdad de las mujeres en todas las esferas de la vida y no simplemente en la cultura pública. Okin pensaba que Rawls pidió muy poco de las religiones cuando simplemente les requirió que aceptaran la plena igualdad de las mujeres como ciudadanas, pero no les pidió, por ejemplo, que aceptaran la igualdad teológica o escatológica de las mujeres.

Por mi parte veo el punto de Okin. Aunque no acepto su argumento, y aunque creo que ella malinterpreta a Rawls en algunos puntos ${ }^{(69)}$, su argumento me parece el mejor contra la forma

(66) John Stuart Mill, The Subjection of Women, ed. Susan Moller Okin (Indianapolis, Ind.: Hackett, 1988), 4.

(67) Mill ciertamente quiere que tanto la cultura como el derecho cambien; hasta qué punto cree que es correcto para el gobierno promulgar una doctrina comprehensiva de igualdad de las mujeres, en contraste con las reformas políticas específicas que él evidentemente favorece, permanece poco claro, y por lo tanto no lo abordaré más aquí.

(68) Susan Moller Okin, "Political Liberalism, Justice and Gender," Ethics 105 (1994): 23-43; Is Multiculturalism Bad for Women? ed. Joshua Cohen, Matthew Howard, y Martha Nussbaum (Princeton, N.J.: Princeton University Press, 1999), 9-24, y su versión más extensa, "Feminism and Multiculturalism: Some Tensions," Ethics 108 (1998): 661-84. La discusión central de Okin se refiere a los mitos fundacionales de la antigua religión greco-romana, el cristianismo, judaísmo y el islam, pero su pretensión teórica es mucho más amplia: "gran parte de la mayoría de las culturas trata de controlar a las mujeres y mantener los roles de género" "Feminism," 667). Una afirmación similar aparece en la versión más corta: "la mayoría de las culturas tienen como uno de sus objetivos principales el control de las mujeres por los hombres" (Is Multiculturalism Bad for Women, 13). A medida que se desarrolla el artículo publicado en Ethics, y Okin se involucra en debates con teóricos que discuten ejemplos de otras religiones (por ejemplo, las discusiones de Kymlicka sobre las prácticas religiosas de las minorías indígenas y la referencia general de Kukathas sobre las culturas inmigrantes) amplía el alcance de su crítica. (La versión del libro, similarmente, discute prácticas nativas en Perú así como en las religiones tradicionales de áfrica) En "Feminism", nota 17, apoya explícitamente la afirmación de dos estudiosas feministas de que "[l]as tradiciones siempre han sido una espada de doble filo para mujeres. El estatus económico y social subordinado y las restricciones a la actividad y la movilidad de las mujeres están integradas en la mayoría de las culturas tradicionales." Mientras que Okin no suele distinguir entre religión y cultura, sus largas discusiones sobre los cuatro mitos fundacionales religiosos hacen hincapié en la religión entendida como un medio de control.

(69) Véase Nussbaum, "Rawls and Feminism," en Cambridge Companion to Rawls, 488-520. 
Martha C. Nussbaum

de liberalismo de Rawls. Uno debe insistir en que el ámbito político (incluidas las escuelas públicas) tendrá derecho a utilizar la argumentación racional para socavar los estereotipos degradantes. Pero probablemente se debe conceder que, en ausencia de una reforma cultural profunda, esta intervención probablemente logre sus resultados más lentamente y con mayor dificultad. Creo que la mejor línea de defensa para Raz consistiría en centrarse en estos casos.

No creo que Okin esté en lo correcto sobre la religión: creo que ahora la mayoría de estas han participado en debates sobre la igualdad de los sexos y los movimientos hacia la igualdad de los sexos a la par que el resto de culturas, modificando sus doctrinas comprehensivas de acuerdo con el cambio en las opiniones sobre la cultura pública que comparten con sus conciudadanos. Pocas han mostrado más resistencia al cambio que las culturas que las rodean ${ }^{(70)}$. (Así también con la mayoría de las doctrinas comprehensivas seculares, que también han sido sexistas.) Algunas incluso han estado por delante de sus culturas circundantes. Más importante aún, sin embargo, también creo que la política no tiene ninguna legitimidad para hablar de la vida después de la muerte, o sobre quién debe ser un sacerdote. (El liberalismo político está estrechamente relacionado con la idea de Locke sobre la adecuada jurisdicción del espacio civil. La relación entre estas dos doctrinas merece un estudio más profundo.) Sin embargo, veo suficiente fuerza en las consideraciones planteadas por Okin (y Mill) para sostener que el debate entre el liberalismo político y el liberalismo comprehensivo es profundo y debe continuar hasta que comprendamos todas las opciones y cuestiones tan bien como podamos. Por lo tanto, todos debemos estar inmensamente agradecidos a Raz y Berlin, por ofrecernos una versión de la alternativa perfeccionista que es tan clara y completa como cualquiera que probablemente veamos en algún tiempo.

\section{Liberalismo Político: Un ejemplo}

Berlin sugiere que el liberalismo perfeccionista es necesario porque las doctrinas comprehensivas que no aceptan los principios liberales de tolerancia y autonomía desestabilizarán la sociedad liberal. Raz sostiene que el perfeccionismo es necesario para la tolerancia, que él describe como implicando un freno de tendencias hostiles o negativas: así, él también plantea preguntas de estabilidad $^{(71)}$. He sugerido que el liberalismo perfeccionista del tipo que defienden es irrespetuoso y que el liberalismo político puede ser estable, siempre que los poseedores de las diversas doctrinas comprehensivas se preocupen suficientemente por el respeto a las personas. Ayuda, entonces, ver que hay formas de liberalismo político que existen y que mantienen unidas a ciertas democracias viables. Por supuesto, ninguna existe en una Sociedad Bien Ordenada de corte rawlsiano, donde los dos principios de la justicia están plenamente implementados; pero se podría decir que ambos están en la etapa del consenso constitucional que Rawls ve como un estadio en el camino hacia consensos entrecruzados $^{(72)}$.

Hay varios ejemplos que se podrían ofrecer a este respecto. Las constituciones tanto de la India como de Sudáfrica son ejemplos muy interesantes de cómo el compromiso por el respeto de las personas puede traducirse en

(70) Incluso en aquellos casos en los que una jerarquía religiosa sigue exhibiendo doctrinas abiertamente sexistas, como, por ejemplo, con la negativa de la Iglesia Católica Romana por ordenar a mujeres, los laicos y grandes partes del clero, en los Estados Unidos en gran número, favorecen el cambio, por lo que ni siquiera debe decirse que la religión católica romana está per se opuesta a la igualdad de los sexos. Es evidente, sin embargo, que el carácter centralizado e internacional de la Iglesia Católica Romana plantea dificultades especiales para el cambio, ya que las culturas públicas de las naciones de las que se extraen muchos de sus miembros no apoyan plenamente la igualdad de las mujeres.

(71) Véase MF, 401-2.

(72) Véase LP, 158-63, para la idea de un consenso constitucional. 
un esquema constitucional que es autónomo en el sentido de Rawls, es decir, no basado en alguna doctrina divisoria religiosa o metafísica, sino sólo en un compromiso práctico respecto de la dignidad humana y los derechos humanos. Sin embargo, en aras de la ilustración, permítanme enfocarme en un solo ejemplo, el tratamiento de la religión bajo el derecho constitucional de los Estados Unidos ${ }^{(73)}$.

Los colonos norteamericanos estaban muy familiarizados con el hecho de que los diferentes ideales, y la búsqueda del ideal por parte de cada grupo, frecuentemente llevaba a la subordinación de los demás: la prohibición, al castigo, o a la exclusión de cargos políticos. Por lo tanto, se dirigieron no sólo a defender la libertad religiosa en la nueva nación, garantizando a todos los ciudadanos el libre ejercicio de su credo, sino también, con el tiempo, se opusieron a todos los establishments religiosos. Estos establishments eran peores cuando amenazaban la libertad, penalizando a la gente por formas de adoración no ortodoxas, o forzándolas a afirmar sentimientos ortodoxos que ellos podían no creer, o atribuyendo condiciones de ortodoxia religiosa a los derechos civiles de una persona o su capacidad para ocupar cargos. Sin embargo, se comprendió rápidamente que incluso un establishment aparentemente benigno fomenta la desigualdad al hacer la afirmación de que el gobierno de la nación respalda una determinada religión. Este respaldo o afirmación es, al mismo tiempo e inevitablemente, un desacuerdo, que crea un grupo dentro y otro fuera. Madison decía, recordemos, que "todos los hombres deben ser considerados como ingresando a la sociedad en iguales condiciones", y creía que incluso un establishment no coercitivo violaba esa igualdad. Madison estaba hablando, en 1785, en oposición a una propuesta para gravar a todos los ciudadanos de Virginia para el apoyo de la Iglesia anglicana ahí establecida. De acuerdo a una propuesta extremadamente blanda, los ciudadanos que no eran anglicanos deberían tener permiso para desviar sus pagos de impuestos hacia sus propias iglesias. No obstante, Madison pensó que el anuncio desnudo de que la Iglesia Anglicana era la iglesia estatal estableció jerarquizaciones y órdenes entre los ciudadanos. En 1984, discutiendo la prohibición de la Constitución de los Estados Unidos sobre el establishment religioso, la jueza Sandra Day O'Connor recapituló la larga tradición Madisoniana en los siguientes términos:

"La Cláusula de Establecimiento [Establishment] prohíbe al gobierno hacer que la adhesión a una religión sea relevante de alguna manera para la posición de una persona en la comunidad política... El respaldo envía el mensaje a los no adherentes de que son forasteros, no plenos miembros de la comunidad política, y un mensaje complementario a los adherentes que son parte, miembros favorecidos de la comunidad política. La desaprobación envía el mensaje opuesto." (Lynch vs. Donnelly, 1984)

De acuerdo con el muy útil análisis de la jueza O'Connor, la pregunta correcta a plantear respecto de cualquier política potencialmente problemática en el área del establecimiento religioso es la siguiente: ¿un observador objetivo, familiarizado con todos los hechos históricos y contextuales relevantes, verá la política en cuestión como una que hace una declaración pública de respaldo o desaprobación, enviando un mensaje de desigualdad? (74). $^{(7)}$.

Aunque hay muchas aproximaciones acerca del propósito y significado de la Cláusula de Establecimiento, creo (y he argumentado) que la formulación de Madison y O'Connor llega al corazón de la cuestión ${ }^{(75)}$. Fundamentalmente, la cláusula trata de la igualdad, la igualdad de

(73) He tratado este ejemplo extensamente en Liberty of Conscience.

(74) Por "enviar el mensaje," O’Connor quiere señalar presumiblemente que la política en cuestión, comunicando la aprobación del gobierno a una doctrina comprehensiva particular seleccionada entre otras, es razonablemente entendida como haciendo la declaración de que esta doctrina es preferida por el gobierno, y que sus adherentes, por lo tanto, viven la vida que prefiere el gobierno, y son un grupo privilegiado de ciudadanos.

(75) Nussbaum, Liberty of Conscience, capítulo 6. 
Martha C. Nussbaum

posición de todas las personas en el ámbito político. Expresa el igual respeto y sostiene que ninguna doctrina comprehensiva da a una persona la pretensión de ser respetada y de la que otra no goce. La Cláusula de Establecimiento, entonces, establece una forma de liberalismo político. Raz podría no aceptarlo, porque le gustaría establecer principios controversiales y sectarios de naturaleza perfeccionista, principios que no serían aceptables para los miembros creyentes de la mayoría de las religiones existentes. Los religiosos existirían en la misma condición de subordinación expresiva descrita por Madison y O'Connor: serían un grupo excluido, tratado por las declaraciones de su gobierno y sus líderes con una calificación desfavorable.

Por supuesto que ninguna idea semejante puede desarrollarse completamente sin controversia política e interpretativa. Pero, en general, esta idea de no subordinación, y la idea concomitante de desaprobación, ha ejercido una influencia poderosa sobre el derecho y la política en general, y ha permitido a los miembros de diversas doctrinas vivir juntos sin tener que pensar si los principios políticos de la nación en la que viven apoyan o niega sus doctrinas religiosas. Ofrece a aquellos que persiguen el ideal de diferentes maneras un lugar de reunión que no denigra ninguno de sus estrategias; y ofrece este mismo lugar de encuentro al humanista secular que posee una doctrina comprehensiva de autonomía, al igual que Raz. Parece dar a la gente de una nación abrumadoramente religiosa como los Estados Unidos una base para el apego a principios políticos fundamentales que no hubieran sido proporcionados por ninguna forma de perfeccionismo: porque cualquier perfeccionismo establecería una religión a expensas de otras, o establecería un principio secular (como el utilitarismo de Bentham o la autonomía de Raz) a expensas de las doctrinas sostenidas por una gran mayoría del pueblo de esta nación.

Berlin sentía claramente la necesidad de un punto de encuentro que pudiera reunir a personas en una sociedad diversa. Sin embargo, dado su respaldo al principio metafísico y controvertido del pluralismo, no pudo dar más que una fina explicación de este terreno común, en la forma de "un mínimo sin el cual las sociedades apenas podrían sobrevivir" (PI, página 15). Berlin menciona sólo algunas de estas proposiciones: la injusticia de la esclavitud y el asesinato ritual, de "las cámaras de gas nazis o la tortura de seres humanos por placer o beneficio, o incluso por el bien político -o incluso el deber de los niños de denunciar a sus padres... o el asesinato insensato" (página 15). Creo que este fundamento es tan mínimo que resulta dudoso que pueda dar cuenta de la estabilidad para una sociedad liberal. En mi opinión, el relato del liberalismo político sobre el terreno común es superior, porque incorpora nociones éticas mucho más sustantivas y organizadoras, como la de igual respeto, y los principios políticos que derivan de ello.

Si el liberalismo político es superior al liberalismo perfeccionista por razones éticas, como he argumentado, y si lo hace mejor aún en el asunto de la estabilidad, no podemos tener ninguna razón para no preferirlo en general. 